\title{
Fluctuations and behaviour of foxes determined by nightlighting. Preliminary results
}

\author{
Jean-Marc WEBER, Stéphane AUBRY, Nicole LACHAT, Jean-Steve MEIA, \\ Claude MERMOD and Alain PARATTE
}

\begin{abstract}
Weber J.-M., Aubry S., Lachat N., Meia J.-S., Mermod C. and Paratte A. 1991. Fluctuations and behaviour of foxes determined by nightlighting. Preliminary results. Acta theriol. 36: 285 - 291 .

Nightlighting was used to determine the fluctuations of a red fox Vulpes vulpes Linnaeus, 1758 population in the Swiss Jura Mountains between July 1987 and April 1990. Number of foxes seen fluctuated according to months and years. It decreased in winter. Fewer foxes were also seen in 1988, likely because of the high human hunting pressure. The behaviour of every fox seen was recorded. Their main activity was hunting and foraging (45\%).
\end{abstract}

Institut de Zoologie, Chantemerle 22, 2000 Neuchâtel 7, Switzerland

Key words: Vulpes vulpes, numbers, behaviour, nightlighting

\section{Introduction}

Nightlighting has been used by game biologists and poachers for many years. Besides the capture of birds or mammals (Labisky 1968), this method enables the census of animal species as different as cottontails (Lord 1959), nightjars (Eltringham and Flux 1971), hares (Salzmann and Salzmann 1973, Barnes and Tapper 1985), deer (Progulske and Duerre 1964) or foxes (Ryszkowski et al. 1973). More recently, Roboly (1985) used nightlighting to study the evolution of fox and feral dog populations in rabies areas in eastern France and Stahl (1990) did an evaluation of nightcounts to monitor a fox population.

To our knowledge, there is no reference about the use of nightlighting to collect some data on animal behaviour. As part of a project on social organization of the red fox Vulpes vulpes Linnaeus, 1758, nightlighting was used to determine long-term fluctuations of the population and the behaviour of individual foxes.

\section{Study area}

The $33 \mathrm{~km}^{2}$ study area is situated in "La Chaux d'Abel" region (Swiss Jura Mountains) $\left(47^{\circ} 09^{\prime} \mathrm{N}, 6^{\circ} 56^{\prime} \mathrm{E}\right)$, ca. $30 \mathrm{~km}$ north of Neuchâtel. In this typically karstic relief, the altitude ranges from $900 \mathrm{~m}$ to $1290 \mathrm{~m}$. The countryside is a mosaic of pastures $(37 \%)$, wooded pastures $(48 \%)$ and spruce Picea abies dominated forests $(15 \%)$. About 80 farms are evenly distributed over the area which is covered with an important road network. 
Tasle 1. Number of foxes seen every month. A, B, C correspond to the part of the night the nightlighting was done (see the text for explanation).

\begin{tabular}{|c|c|c|c|c|}
\hline Month/Year & A & B & $\mathrm{C}$ & Total \\
\hline $7 / 87$ & 4 & 8 & 8 & 20 \\
\hline $8 / 87$ & 11 & 9 & 13 & 33 \\
\hline $9 / 87$ & 10 & 12 & 9 & 31 \\
\hline $10 / 87$ & 14 & 9 & 11 & 34 \\
\hline $11 / 87$ & 6 & 0 & 6 & 12 \\
\hline $12 / 87$ & 2 & 5 & 3 & 10 \\
\hline $1 / 88$ & 2 & 2 & 4 & 8 \\
\hline $2 / 88$ & 1 & 0 & 1 & 2 \\
\hline $3 / 88$ & 2 & 2 & 0 & 4 \\
\hline $4 / 88$ & 2 & 1 & 3 & 6 \\
\hline $5 / 88$ & 9 & 2 & 5 & 16 \\
\hline $6 / 88$ & 0 & 4 & 4 & 8 \\
\hline $7 / 88$ & 7 & 8 & 6 & 21 \\
\hline $8 / 88$ & 1 & 0 & 2 & 3 \\
\hline $9 / 88$ & 6 & 3 & 2 & 11 \\
\hline $10 / 88$ & 4 & 5 & 3 & 12 \\
\hline $11 / 88$ & 3 & 7 & 4 & 14 \\
\hline $12 / 88$ & 0 & 3 & 4 & 7 \\
\hline $1 / 89$ & 3 & 0 & 0 & 3 \\
\hline $2 / 89$ & 6 & 2 & 0 & 8 \\
\hline $3 / 89$ & 5 & 7 & 2 & 14 \\
\hline $4 / 89$ & 1 & 3 & 4 & 8 \\
\hline $5 / 89$ & 6 & 5 & 3 & 14 \\
\hline $6 / 89$ & 6 & 15 & 15 & 36 \\
\hline $7 / 89$ & 9 & 5 & 11 & 25 \\
\hline $8 / 89$ & 4 & 7 & 8 & 19 \\
\hline $9 / 89$ & 8 & 1 & 6 & 15 \\
\hline $10 / 89$ & 20 & 9 & 10 & 39 \\
\hline $11 / 89$ & 11 & 14 & 8 & 33 \\
\hline $12 / 89$ & 9 & 6 & 8 & 23 \\
\hline $1 / 90$ & 5 & 3 & 9 & 17 \\
\hline $2 / 90$ & 11 & 14 & 2 & 27 \\
\hline $3 / 90$ & 12 & 4 & 6 & 22 \\
\hline $4 / 90$ & 8 & 8 & 11 & 27 \\
\hline Total & 208 & 163 & 151 & \\
\hline Mean & 6.12 & 5.38 & 5.62 & \\
\hline SD & 4.49 & 4.19 & 3.91 & \\
\hline
\end{tabular}




\section{Material and methods}

A $26 \mathrm{~km}$ standard circuit was chosen to be representative of the study area. Furthermore it had to be passable all along the year, as the nightlighting was made with a slow moving car $(10-15 \mathrm{~km} / \mathrm{h})$. The countryside, on both sides of the car, was lighted with a portable spotlight and regularly swept by the beam within a range of $400 \mathrm{~m}$. The observations were done with $10 \times 40$ binoculars.

The sampling occured every month, three nights ( 1 night $=1$ session $)$ in a row, according to the following scheme: 1 st night (A): from $9.00 \mathrm{pm}$ to midnight; 2 nd night (B): from midnight to $3.00 \mathrm{am}$; 3rd night (C): from $3.00 \mathrm{am}$ to $6.00 \mathrm{am}$. When the weather did not permit the nightlighting (heavy rain, fog, etc.), the session was postponed to the next night.

From July 1987 to April 1990 every fox seen was counted. Since September 1988, we systematically recorded - as far as the conditions permitted it - behaviour of foxes. Five categories of activity were differentiated: (1) hunting and foraging, (2) locomotion: direct travel without foraging or obvious flight, (3) flight, (4) rest, (5) interactions: intra- and interspecific contacts.

\section{Results}

A hundred and two nightlighting sessions were made (Table 1). This represents a total of 522 fox observations which were regularly distributed between the 3 sampling periods (A, B,

C) (one way ANOVA: $p=0.763$ ).

The number of foxes seen fluctuated between months $\left(\chi^{2}=33.9\right.$, d.f. $=6, p<0.01$; Fig. 1). It decreased every winter. Fewer foxes were seen during the July - August periods, but the samples were too small for analysis.

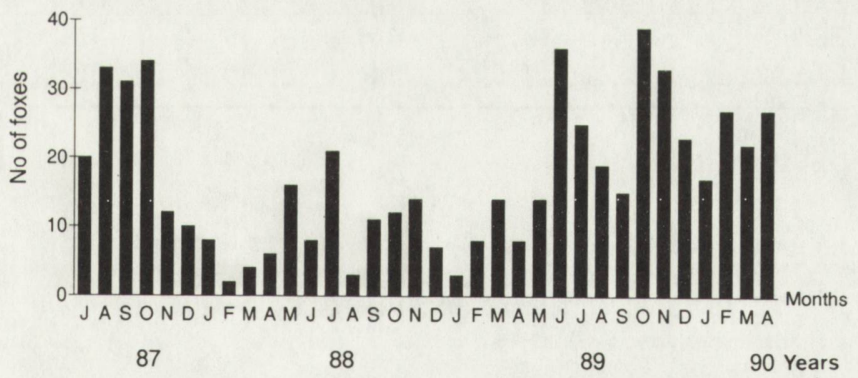

Fig. 1. Fluctuations of number of foxes observed.

There also were yearly fluctuations. A decrease occurred in 1988. From about 50 estimated foxes living in the study area end 1987, 30 were shot by hunters during the winter (Paratte 1989). Thus, only two breeding dens were occupied in 1988 in the whole area, instead of 10 in 1987. The population recovered very quickly, since 12 breeding sites were known in 1989.

The behaviour of 345 foxes was recorded (Fig. 2). The frequency of occurrence of each activity type did not differ according to the part of the night it was recorded $\left(\chi^{2}=4.32\right.$, d.f. $=8, p>0.05$; Table 2).

"Hunting and foraging" (157/345) was observed significantly more often than any other activity (Table 3). During the years 1988/89, foxes were systematically feeding on the fossorial form of the water vole Arvicola terrestris scherman (J.-M. Weber et al., in prep.). Capture of 


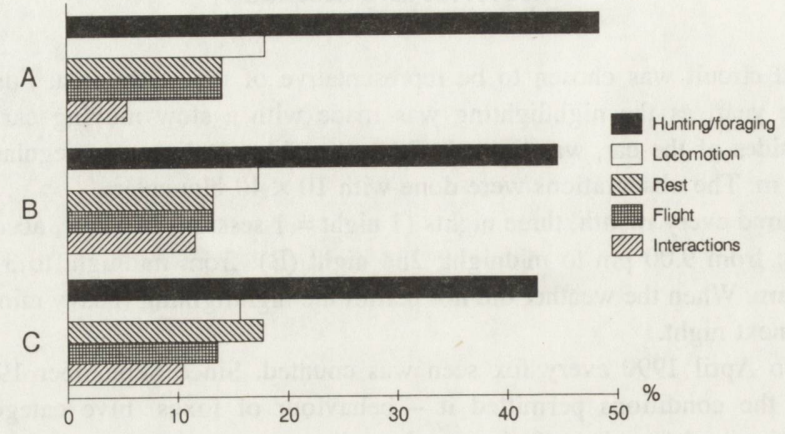

Fig. 2. Frequency of occurrence (\%) of different activity types during the 3 sampling periods (A: $9.00-12.00$ p.m.; B: 0.00 -3.00 a.m.; C: $3.00-6.00$ a.m.).

Table 2. Activity types of foxes recorded during the 3 sampling periods (A, B, C).

\begin{tabular}{lcccc}
\hline Type of activity & A & B & C & Total \\
\hline Hunting/foraging & 62 & 54 & 41 & 157 \\
Locomotion & 23 & 21 & 15 & 59 \\
Rest & 18 & 16 & 17 & 51 \\
Flight & 18 & 16 & 13 & 47 \\
Interactions & 7 & 14 & 10 & 31 \\
\hline
\end{tabular}

Table 3. Comparison $\left(\chi^{2}\right)$ of the proportion of different activity types. H/F: Hunting/foraging, L: Locomotion, F: Flight, R: Rest, I: Interactions, ns: non significant, + : significantly different $(0.05>p>0.01),++$ : significantly different $(p<0.01)$.

\begin{tabular}{ccccc}
\hline $\mathrm{H} / \mathrm{F}$ & $\begin{array}{c}63.41 \\
++\end{array}$ & $\begin{array}{c}82.69 \\
++\end{array}$ & $\begin{array}{c}75.88 \\
++\end{array}$ & $\begin{array}{c}114.24 \\
++\end{array}$ \\
\cline { 2 - 4 } $\mathrm{L}$ & $\begin{array}{c}1.35 \\
\mathrm{~ns}\end{array}$ & $\begin{array}{c}0.53 \\
\mathrm{~ns}\end{array}$ & $\begin{array}{c}9.32 \\
++\end{array}$ \\
\cline { 2 - 4 } & $\mathrm{F}$ & $\begin{array}{c}0.11 \\
\mathrm{~ns}\end{array}$ & $\begin{array}{c}3.25 \\
\mathrm{~ns}\end{array}$ \\
\cline { 3 - 4 } & & $\mathrm{R}$ & $\begin{array}{c}5.00 \\
+\end{array}$ \\
\cline { 3 - 5 } & & & & $\mathrm{I}$ \\
\hline
\end{tabular}


this rodent was observed forty times. Besides it is likely that most other observations involved both fox and water vole. The vole was indeed present in high densities (700 - 1000 ind./ha) on the whole area, particularly in open areas. However we also observed foxes hunting earthworms (3) and insects (2).

"Locomotion", "Flight" and "Rest" occurred in about the same frequency, whereas "Interactions" was less frequent (Tables 2 and 3). "Interactions" mainly involved fox cubs, but interactions with other carnivores (cat, badger, stone marten) were also observed. However this will be presented and discussed in another paper.

\section{Discussion}

According to most authors, nightlighting is a useful and reliable technique to give relative population estimates (Progulske and Duerre 1964, Eltringham and Flux 1971, Salzmann and Salzmann 1973). Although it does not give any absolute density, it allows to compare populations of different areas (Roboly 1985) or to follow the evolution of a population in the same area: seasonal and long-term fluctuations are obviously revealed (Lord 1961, Eltringham and Flux 1971, Stahl and Migot 1990). However many factors could influence the counts.

Fewer foxes were seen in winter. This could be the result of natural mortality and hunting. Paratte (1989) emphasized the great influence of hunters on fox population in our study area and according to Stahl and Migot (1990) even a small fox removal influenced the indices of abundance. On the other hand this decrease might also proceed from a behavioural modification: we noticed that radio-tagged foxes were active mostly in sheltered areas during the winter. There the snow cover is not as important as in open areas and thus it may allow more effective travelling and hunting.

We also observed a reduction in fox seen in July or in August. At that time of the year, the farmers leave the grass to grow up to produce hay. Thus it may reach 1 meter high and easily hide a fox. The autumnal increase corresponds to the dispersal of cubs.

Others important influential factors are weather conditions (Newman 1959, Fafarman and Whyte 1978) and time of day (Lord 1959, Salzmann and Salzmann 1973). Though the authors generally agree about the influence of weather factors on the counts, this influence is highly variable and certainly depends on the species. Progulske and Duerre (1964) found a correlation between temperature and deer numbers, while Salzmann and Salzmann (1973) did not find one with brown hares. Wind speed seems to have little effect on cottontail night counts whereas they tend to be greater during rain fall (Fafarman and Whyte 1979) or just after (Newman 1959). There is also a positive correlation between snow and rabbit or hare counts (Fafarman and Whyte 1979, Salzmann and Salzmann 1973). According to Ables (1969), precipitation causes a decrease of fox activity while others factors have little effect. Only extreme weather conditions could have a significant effect on fox counts (Stahl 1990). By postponing the nightlighting sessions occurring during rain, snow fall and fog - this mainly because of the poor visibility we get in such conditions - we suppressed a potential influence of these factors on fox counts. 
Counts could also be influenced by the time of day. Lord (1959) observed more cottontails during night (one hour after dark) than in early morning (dawn). Early hours of darkness were also better for deer counts than others (Progulske and Duerre 1964). This obviously depends on animal activity pattern.

The fox is known to have a bimodal nocturnal pattern, the two peaks occurring at dusk and dawn (Ables 1969, Artois 1985). Therefore we should expect to count more individuals in the first and third nightlighting sessions, the more so as most of observed foxes were active. However our results did not show any significant difference between the three sessions counts. This confirms the results of Stahl (1990). Furthermore, the frequency of some activity categories did not differ according to the time they were recorded. In our study area, foxes seem to forage and rest as much in early night than in mid- or late night. Radio-tagged individuals did not show any obvious bimodal pattern (J.-M. Weber et al., in prep.). Ables (1969) emphasizes that peaks of foxes correspond to peaks in prey activity. This could explain our results, but unfortunately we have not got enough evidence of it yet.

At last, it is likely that fox counts could be influenced by prey availability and distribution. Nightlighting sessions were made when water vole populations were in high density. These rodents live in open areas which constitute foxes main feeding patches as it was determined with radio-tagged foxes (J.-M. Weber et al., in prep.). Furthermore, during the nightlighting sessions, most of the observed foxes were hunting or foraging. Hence one could await that foxes would move away from those areas when the rodents are in low density and would forage where the potential prey are present (i.e. in areas where nightlighting is not effective). However only a long-term survey could reveal fluctuations of this origin since the water vole has pluriannual cycles [on average: 6 years in the Jura mountains (Debrot 1981)]. Therefore it is necessary to be cautious with a long-term sampling done at regular interval, i.e. every February or March as proposed by Stahl and Migot (1990), without taking in account the prey factor.

Only few foxes $(51 / 345)$ responded to the lighting. As we frequently use this method in our study area, it is likely that most individuals gradualy get used to it.

The nightlighting provides reliable data on populations state. Seasonal and yearly fluctuations may be revealed as far as the sampling is rigorous: standard route, low speed, same observers, monthly counts and "favourable" weather conditions. Besides, this technique allows also to collect valuable behavioural informations. Hence the interest to associate it with other field techniques (i.e. animal tagging, radio-tracking).

Acknowledgements: We would like to thank Dr. R. Hewson for his useful comments on the manuscript. This study was partly financed by the Federal Office of Environment, Forests and Landscape.

\section{References}

Ables E. D. 1969. Activity studies of red foxes in southern Wisconsin. J. Wildl. Manage. 33: 145 - 153.

Artois M. 1985. Utilisation de l'espace et du temps chez le renard (Vulpes vulpes) et le chat forestier (Felis silvestris) en Lorraine. Gibier Faune Sauvage 3: 33 - 57.

Barnes R. F. W. and Tapper S. C. 1985. A method for counting hares by spotlight. J. Zool., Lond. 206: $273-276$. 
Debrot S. 1981. Trophic relations between the stoat (Mustela erminea) and its prey, mainly the water vole (Arvicola terrestris scherman). [In: Worldwide Furbearer Conference Proceedings. J. A. Chapman and D. Pursley, eds]. Frostburg, Maryland, Vol. II: 1259 - 1289.

Eltringham S. K. and Flux J. E. C. 1971. Night counts of hares and other animals in East Africa. E. Afr. Wildl. J. 9: $67-72$.

Fafarman K. R. and Whyte R. J. 1979. Factors influencing nighttime roadside counts of cottontail rabbits. J. Wildl. Manage. 43: 765 - 767.

Labisky R. F. 1968. Nightlighting: its use in capturing pheasants, prairie chickens, bobwhites and cottontails. Ill. Nat. Hist. Survey Biol. Notes 62: 1- 12 .

Lord R. D., Jr 1959. Comparison of early morning and spotlight roadside censuses for cottontails. J. Wildl. Manage. 23: 458 - 460.

Lord R. D., Jr 1961. Seasonal changes in roadside activity of cottontails. J. Wildl. Manage. 25: 206 - 209.

Newman D. E. 1959. Factors influencing the winter roadside count of cottontails. J. Wildl. Manage. 23: $290-294$.

Progulske D. R. and Duerre D. C. 1964. Factors influencing spotlighting counts of deer. J. Wildl. Manage. 28: $27-34$.

Paratte A. 1989. Etude d'une population de renards dans le Jura. Travail de licence non publié, Université de Neuchâtel: 1 - 78 .

Ryszkowski L., Goszczyński J. and Truszkowski J. 1973. Trophic relationships of the common vole in cultivated fields. Acta theriol. 18: $125-165$.

Roboly O. 1985. Etude des populations de certains canidés sauvages ou errants l'occasion du tir de nuit. Rev. Ecol. (Terre et Vie) 40: $187-188$.

Salzmann I. and Salzmann H. C. 1973. Erste Erfahrungen bei Feldhasenzählungen mit Scheinwerfern. Jahrbuch des Naturhist. Museums der Stadt Bern 5: $201-216$.

Stahl P. 1990. Suivi de l'abondance d'une population de renards (Vulpes vulpes) par comptages nocturnes: évaluation de la méthode. Gibier Faune Sauvage 7: 293 - 309.

Stahl P. and Migot P. 1990. Variabilité et sensibilité d'un indice d'abondance obtenu par comptages nocturnes chez le renard (Vulpes vulpes). Gibier Faune Sauvage 7: 311 - 323.

Received 6 November 1990, accepted 20 August 1991. 